\title{
Meta Analysis: Donepezil in the Treatment of Cognitive Impairment and Dementia in Patients with Parkinson's Disease
}

\author{
Ela A. Barcelon, Leah L. Shiong Shu and Paul Matthew D. Pasco
}

Department of Neurosciences, College of Medicine and Philippine General Hospital, University of the Philippines Manila

\begin{abstract}
Objective. Evaluate the efficacy and safety of Donepezil in improving cognitive function of patients with Parkinson's disease diagnosed to have cognitive impairment or dementia.

Methods. Meta-analysis of randomized controlled trials comparing Donepezil versus placebo in the management of Parkinson's disease patients with cognitive impairment or dementia. Mean differences were computed using RevMan Version 5.1.

Results. Fifty-five studies were screened for inclusion in this meta-analysis. Only four studies met the inclusion and exclusion criteria. Administration of Donepezil $10 \mathrm{mg} / \mathrm{tab}$ for at least 4 weeks showed statistically significant improvement in the cognitive function of Parkinson's disease patients with dementia or cognitive impairment in terms of MMSE. There were no significant differences in the other scales measured. Incidence of adverse events was found to be higher in the Donepezil group, but this was not statistically significant.
\end{abstract}

Conclusion. This study successfully demonstrated the efficacy of Donepezil in cognitively impaired Parkinson's disease patient in the improvement of MMSE without significant impact on motor symptoms.

Key Words: Donepezil, Parkinson's Dementia, dementia, Parkinson's Disease, cognitive impairment

\section{Introduction}

Parkinson's disease (PD) affects almost $1 \%$ of the population aged 65 years old and above worldwide. ${ }^{1}$ The range of incidence rate of PD dementia is from $4.2 \%$ to $9.5 \%$ per year. ${ }^{2,3}$ The prevalence rate of PD dementia ranges from $10 \%$ to $40 \%$, depending on the sample population and criteria used. On the other hand, due to the lack of universal criteria to detect mild cognitive impairment in $\mathrm{PD}$, the

Poster presented at the 17th International Congress of Parkinson's Disease and Movement Disorders, June 16-20, 2013, Sydney, Australia.

Corresponding author: Ela A. Barcelon, MD

Department of Neurosciences

Philippine General Hospital

University of the Philippines Manila

Taft Avenue, Ermita, Manila 1000 Philippines

Telefax No.: +6325548462

Email: elabarcelon@gmail.com prevalence of mild cognitive impairment (MCI) in PD remains unclear and ranges from $10 \%$ to $95 \%{ }^{4-11}$

Nevertheless, both forms of cognitive dysfunction in patients with PD imposes a great impact on the quality of life not only of the patient but also of the caregivers, family, and other members of the social support group of the patient. ${ }^{12,13}$

The neuropathophysiological substrate of cognitive dysfunction in PD involves interaction between neurotransmitters, as well as complex cerebral circuits. However, their interaction is not fully understood and not well established. Several pathologic findings have been deemed contributory to the cognitive impairment seen in some PD patients. These include (1) interruption of the frontal-subcortical dopaminergic circuits due to the progressive loss of dopaminergic neurons in the substantia nigra, (2) destruction of the neurons in the nucleus basalis of Meynert leading to decreased cholinergic activity both in cortical areas and in the basal telencephalon, (3) noradrenergic and serotonergic neurons degeneration. ${ }^{14,15,16}$

Among the three pathomechanisms mentioned above, pharmacologic management of PD dementia has drawn attention to cholinergic deficiency. In view of improving the quality of life of PD patients, the great need to halt or treat the progressive cognitive decline seen in PD has paved the way for studies focusing on cholinergic deficiency. Choline esterase inhibitors are one of the classes of drugs that have been experimented on dementia. ${ }^{15}$ This class of drug includes donepezil and rivastigmine.

Donepezil has specific activity for AChE. The unique piperidine-based structure of Donepezil makes it chemically and pharmacologically distinct from other cholinesterase inhibitors making it highly selective for brain AChE and has no effect on cholinesterases from cardiac muscle or intestinal smooth muscle, and has only marginal effect on striatal muscle cholinesterase. ${ }^{17,18,19}$ This makes donepezil very effective in increasing brain acetylcholine levels which has been associated with improved performance in behavioral, learning, and memory function tests in rats with experimentally induced cholinergic hypofunction. ${ }^{20,19}$

In terms of pharmacokinetics, once-daily administration of the drug allows achievement of significant AChE inhibition throughout the dosing interval, even after the first-dose administration. Steady-state concentrations of the 
drug are achieved after 14-21 days of once-daily administration..$^{21}$

Donepezil has been proven effective in patients with Alzheimer's disease. ${ }^{15}$ However, its role in the management of cognitive impairment in other neurodegenerative diseases such as Parkinson's disease and diffuse Lewy body dementia is not well established. Therefore, this metaanalysis aims to evaluate the efficacy of Donepezil in improving cognitive function of patients with Parkinson's disease diagnosed to have cognitive impairment or dementia.

\section{Methods}

\section{Studies}

Criteria for inclusion of published studies were (1) adequate allocation concealment, blinding of interventions, and assessment, (2) including patients older than 40 years of age (3) with a clinical diagnosis Parkinson's disease, (4) diagnosed to have cognitive impairment by baseline MMSE scores of 10-26 (5) given Donepezil of any dose for at least 10 weeks compared to placebo.

\section{Outcome Measures}

\section{Primary Outcomes}

Measure of cognitive improvement by any of the following scales: Alzheimer's Disease Assessment Scalecognitive subscale (ADAS-Cog), Mini-Mental Status Examination (MMSE), Clinician's Interview Based Impression Change (CIBC+), Brief Test of Attention (BTA).

\section{Secondary Outcomes}

Worsening of motor symptoms by UPDRS (Unified Parkinson's Disease Rating Scale) Motor Subsection. Adverse events were also taken into account.

\section{Search strategy, study selection, and data extraction}

Three independent reviewers searched, selected studies and extracted data. Online databases searched included PUBMED, Cochrane Central Register of Controlled Trials, LILACS were browsed to search for studies including 2002 up to the present year, 2012. In order to ensure data acquired was as complete as possible, authors were contacted through email and asked for raw data. Selection of studies and data extraction was done independently by the three reviewers and cross-checked for accuracy.

\section{Statistical analyses}

We performed five subgroup analyses. Data was analyzed using Review Manager Software Version 5.1 to generate forest plot for each of the five scales.

For the primary outcome, all four studies utilized MMSE, two of the four had ADAS-Cog, BTA, and CIBC. For the secondary outcome, all four studies utilized UPDRS Motor Subsection to measure affectation of the Parkinsonian symptoms. However, the study of Dubois et al. 2012 did not provide the UPDRS motor scores at the end of the trial (week 24).

\section{Results}

A total of 55 clinical studies were screened for possible inclusion in this meta-analysis (Figure 1). All 55 studies looked into the use of cholinesterase inhibitors in the management of cognitive impairment in patients with neurodegenerative disorders such as Parkinson's disease and diffuse Lewy body disease.
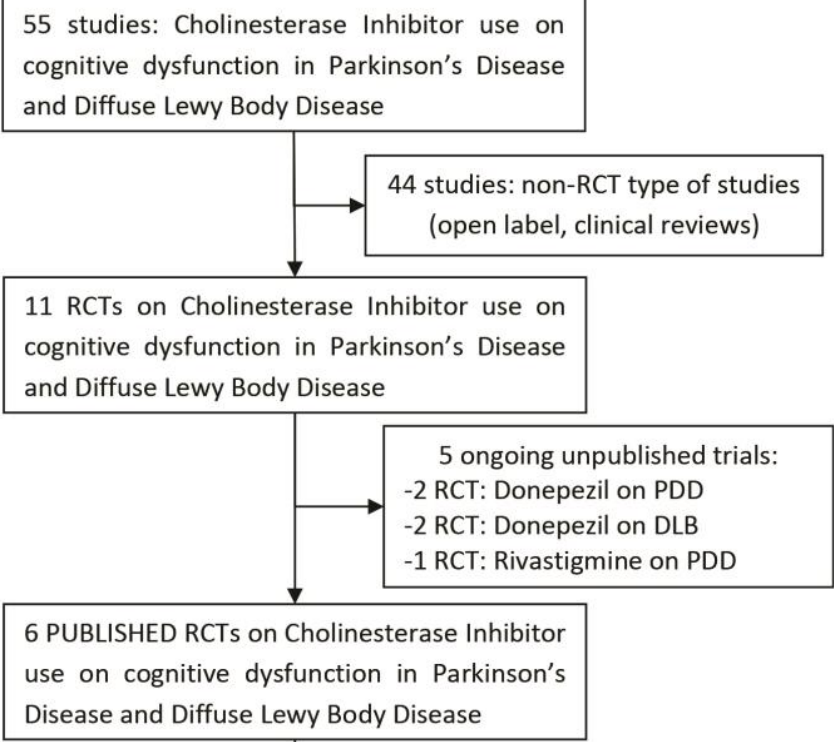

\begin{tabular}{|l|l|}
2 RCTs on Rivastigmine: \\
-1 RCT on PDD \\
-1 RCT on probable DLB
\end{tabular}

4 PUBLISHED RCTs on the use of DONEPEZIL

in the treatment of cognitive impairment in

Parkinson's Disease

Figure 1. Literature Review Flow Diagram

Forty-three (43) studies were excluded because they were not RCTs. Six trials are still ongoing and remain unpublished. Of the six studies, two studies are RCTs investigating the efficacy of Donepezil on the management of PD dementia (Anon 2004a and Burn 2009) and were not included in this meta-analysis.

Of the six published RCTs on cholinesterase inhibitors, two studies used Rivastigmine as the treatment arm, hence was excluded. Of the four studies included, only Dubois 2012 responded and provided complete raw data for analysis. 


\section{Description of Studies}

A total of four studies met our inclusion and exclusion criteria. All the studies used were randomized controlled trials which used Donepezil as the treatment arm compared to placebo on the other. Two studies, Ravina 2005 and Dubois 2012, included Parkinson's disease patients with dementia only while the other two studies, Leroi 2004 and Aarsland 2002, included those with mild cognitive impairment and dementia. The Dubois 2012 study is the final published version of Dubois 2007. Table 1 summarizes the characteristics of the studies included in this metaanalysis.

Table 1. Summary of Studies on Donepezil in Parkinson's Disease with Cognitive Impairment

\begin{tabular}{|c|c|c|c|c|}
\hline Study Name & DUBOIS & RAVINA & LEROI & AARSLAND \\
\hline Publication Date & May 2012 & 2005 & 2004 & 2002 \\
\hline Title / Name & $\begin{array}{l}\text { Donepezil in Parkinson's Disease } \\
\text { Dementia: A Randomized, } \\
\text { Double-Blind Efficacy and Safety Study }\end{array}$ & $\begin{array}{l}\text { Donepezil for dementia in } \\
\text { Parkinson's disease: a } \\
\text { randomized, double blind, } \\
\text { placebo controlled, crossover } \\
\text { study }\end{array}$ & $\begin{array}{l}\text { Randomized placebo-controlled } \\
\text { trial of donepezil in cognitive } \\
\text { impairment in Parkinson's } \\
\text { disease }\end{array}$ & $\begin{array}{l}\text { Donepezil for cognitive } \\
\text { impairment in Parkinson's } \\
\text { disease: a randomized } \\
\text { controlled study }\end{array}$ \\
\hline Authors & $\begin{array}{l}\text { Bruno Dubois, MD, * Eduardo Tolosa, } \\
\text { MD, PhD, Regina Katzenschlager, MD, } \\
\text { Murat Emre, MD, Andrew J. Lees, MD, } \\
\text { FRCP, Gu “" nther Schumann, MD, } \\
\text { Emmanuelle Pourcher, MD, Julian Gray, } \\
\text { MS, Gail Thomas, Jina Swartz, MD, PhD, } \\
\text { Timothy Hsu, MD, and Margaret L. } \\
\text { Moline, PhD10 }\end{array}$ & $\begin{array}{l}\text { B Ravina, M Putt, A Siderowf, J } \\
\text { T Farrar, M Gillespie, A } \\
\text { Crawley, H H Fernandez, } \\
\text { M M Trieschmann, S } \\
\text { Reichwein, T Simuni }\end{array}$ & $\begin{array}{l}\text { Iracema Leroi *, Jason Brandt, } \\
\text { Stephen G. Reich , Constantine } \\
\text { G. Lyketsos, Stephen Grill, } \\
\text { Richard Thompson4 } \\
\text { and Laura Marsh2 }\end{array}$ & $\begin{array}{l}\text { D Aarsland, K Laake, J P } \\
\text { Larsen, C Janvin }\end{array}$ \\
\hline Research Center & 108 centers in 13 countries & 4 centers & 2 centers & 1 center \\
\hline Site & $\begin{array}{l}\text { Germany \& Austria, Spain, Russia, UK, } \\
\text { France, Australia, New Zealand, South } \\
\text { Africa, Canada, Italy, Belgium, Portugal }\end{array}$ & $\begin{array}{l}\text { NINDS (National Institute of } \\
\text { Neurological Disorders and } \\
\text { Stroke), Brown University, } \\
\text { University of Pennsylvania and } \\
\text { Northwestern University }\end{array}$ & $\begin{array}{l}\text { Outpatient neurology clinics in } \\
\text { John Hopkins and community- } \\
\text { based neurology practices in } \\
\text { Baltimore }\end{array}$ & $\begin{array}{l}\text { Outpatient Clinic in } \\
\text { Department of Neurology } \\
\text { at the General Hospital of } \\
\text { Rogaland, Stavanger, } \\
\text { Norway }\end{array}$ \\
\hline $\mathbf{N}$ & 550 & 19 & 16 & 14 \\
\hline \multicolumn{5}{|l|}{ Inclusion Criteria } \\
\hline Age & $>40$ years old & $>40$ years old & & $45-95$ years old \\
\hline $\begin{array}{l}\text { Clinical Diagnosis } \\
\text { of PD based on }\end{array}$ & Queen Square Brain Bank Criteria & Not mentioned & $\begin{array}{l}\text { United Kingdom Brain Bank } \\
\text { Criteria }\end{array}$ & Not mentioned \\
\hline Hoeh \& Yahr & II-IV & Not mentioned & $<=$ IV & $<\mathrm{V}$ \\
\hline $\begin{array}{l}\text { Dementia based on } \\
\text { DSM IV }\end{array}$ & Yes $>1$ year & yes & Yes & yes \\
\hline MMSE & $10-26$ & $17-26$ & $>10$ & $16-26$ \\
\hline $\begin{array}{l}\text { Cognitive } \\
\text { Impairment }\end{array}$ & & & Yes & $\begin{array}{l}\text { Clinical evidence of } \\
\text { memory decline \& at least } \\
1 \text { other category of } \\
\text { cognitive function } \\
\text { Onset should be }>1 \text { year }\end{array}$ \\
\hline Exclusion Criteria & $\begin{array}{l}\text { Major depression } \\
\text { Dementia with Lewy Body } \\
\text { Alzheimer's Disease } \\
\text { Previous AchEI use } \\
\text { allergy }\end{array}$ & & & $\begin{array}{l}\text { Brain disease other than PD } \\
\text { Taking anticholinergics or } \\
\text { psychotropic agents }\end{array}$ \\
\hline Intervention & Donepezil & Donepezil & Donepezil & Donepezil \\
\hline Dose & $5 \mathrm{mg}, 10 \mathrm{mg}$ & $10 \mathrm{mg}$ & $10 \mathrm{mg}$ & $5-10 \mathrm{mg}$ \\
\hline Duration of Treatment & 24 weeks & 10 weeks & 18 weeks & 10 weeks \\
\hline Monitoring & Week 4 , week 8 , week 12 , week 24 & $\begin{array}{l}\text { Week } 1 \text {, week } 7 \text {, week } 10 \text {, week } \\
16 \text {, week } 23 \text {, week } 26\end{array}$ & Every 6 weeks & Week 6, week 10 \\
\hline $\begin{array}{l}\text { Scales Used (Primary } \\
\text { \& Secondary } \\
\text { Outcomes) }\end{array}$ & $\begin{array}{l}\text { ADAS-Cog } \\
\text { CIBC } \\
\text { BTA } \\
\text { D-KEFs } \\
\text { MMSE } \\
\text { DAD } \\
\text { SE } \\
\text { NPI } \\
\text { UPDRS } \\
\text { CGIC-PD }\end{array}$ & $\begin{array}{l}\text { ADAS-Cog } \\
\text { MMSE } \\
\text { MDRS } \\
\text { CGI } \\
\text { BPRS } \\
\text { UPDRS }\end{array}$ & $\begin{array}{l}\text { NART } \\
\text { MMSE } \\
\text { DRS } \\
\text { BTA } \\
\text { TMT-A } \\
\text { TMT-B } \\
\text { HVLT } \\
\text { VMI } \\
\text { UPDRS } \\
\text { CSDD }\end{array}$ & $\begin{array}{l}\text { MMSE } \\
\text { CIBC } \\
\text { NPI } \\
\text { UPDRS }\end{array}$ \\
\hline Conclusion & $\begin{array}{l}\text { Donepezil treatment improved } \\
\text { cognitive function \& global status in } \\
\text { patients with PDD }\end{array}$ & $\begin{array}{l}\text { There is modest benefit on } \\
\text { aspects of cognitive function } \\
\text { and that donepezil is well- } \\
\text { tolerated }\end{array}$ & $\begin{array}{l}\text { Donepezil has beneficial effect } \\
\text { on memory and may improve } \\
\text { other cognitive deficits in } \\
\text { patients with PD and cognitive } \\
\text { impairment. Tolerability is } \\
\text { variable especially in increasing } \\
\text { doses. }\end{array}$ & $\begin{array}{l}\text { Donepezil improves } \\
\text { cognition and seems to be } \\
\text { well tolerated and does not } \\
\text { worsen parkinsonism }\end{array}$ \\
\hline
\end{tabular}




\section{Effects of Intervention}

Comparison of the mean change in ADAS-Cog, as shown in Figure 2 (higher score in ADAS-Cog indicates a more severe cognitive dysfunction), between Donepezil and placebo showed a trend favoring Donepezil (WMD=-1.31, CI -2.69-0.06). However, this was not statistically significant $(\mathrm{p}=0.06)$. On the other hand, the change in MMSE, as shown in Figure 3 (higher score indicates better cognitive function), between the two interventions was statistically significant $(\mathrm{p}<0.00001)$ favoring Donepezil (WMD=1.53, CI 1.06-2.06). BTA (Figure 4) showed that the interventions had no effect (WMD=1.01, CI 0.57, 1.45) with $\mathrm{p}<0.00001$. Other scales such as CIBC (Figure 5) and UPDRS (Figure 6) were not statistically significant with $\mathrm{p}$ values of 0.010 and 0.91 , respectively.

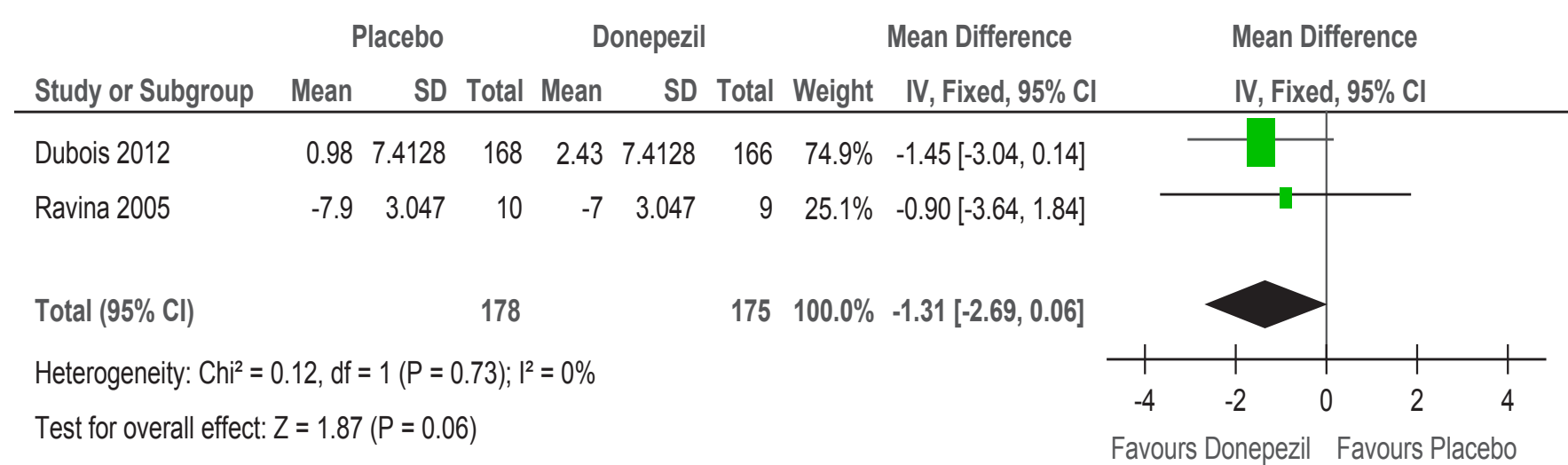

Figure 2. Comparison of the Mean Change in ADAS-Cog Scores

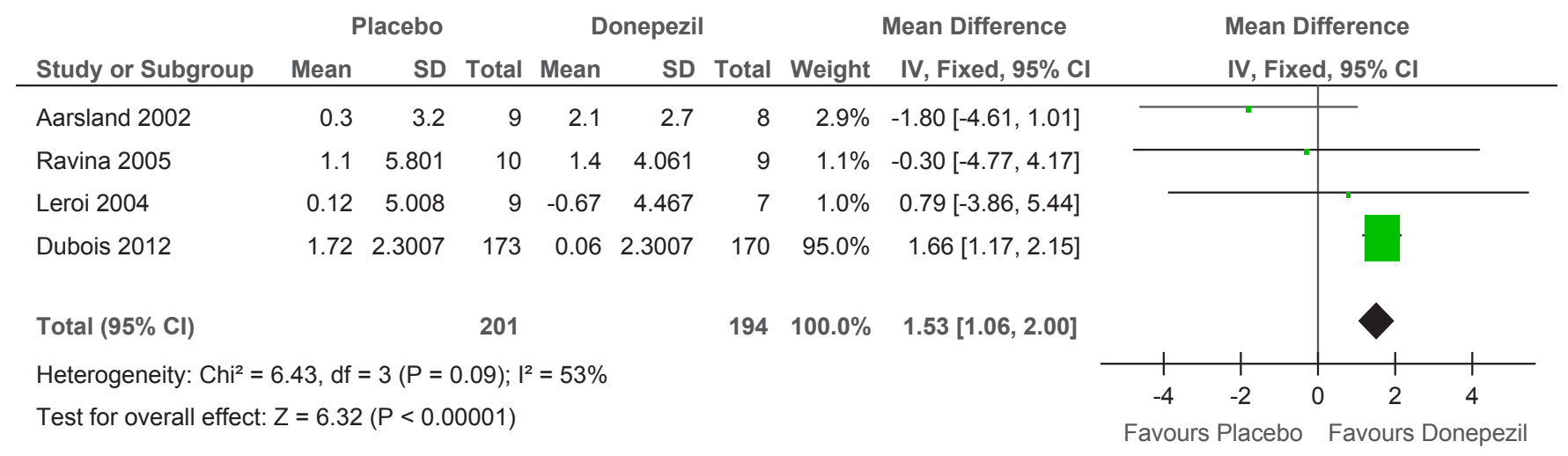

Figure 3. Comparison of the Mean Change MMSE Scores

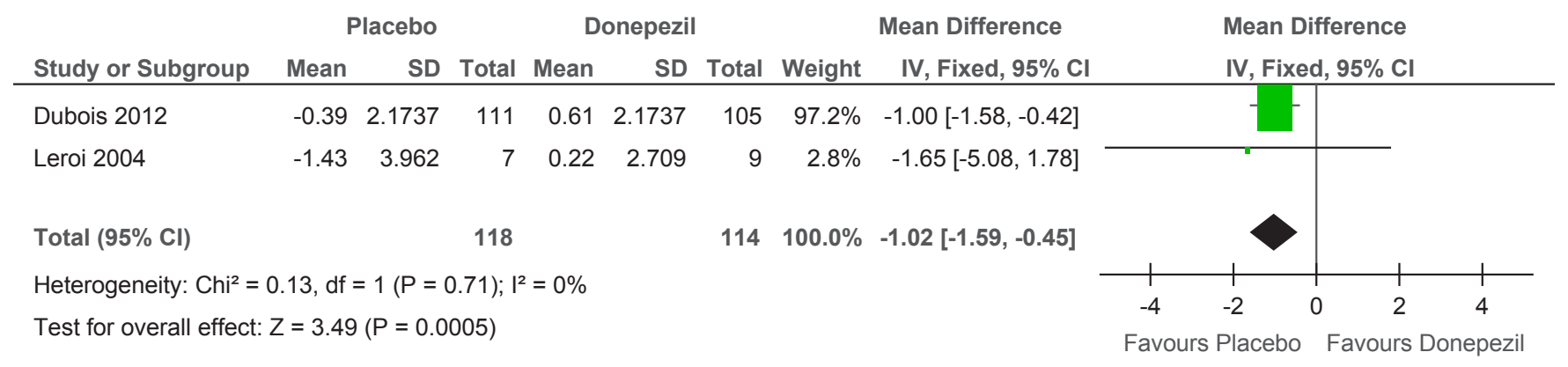

Figure 4. Comparison of the Mean Change in Brief Test of Attention Scores 


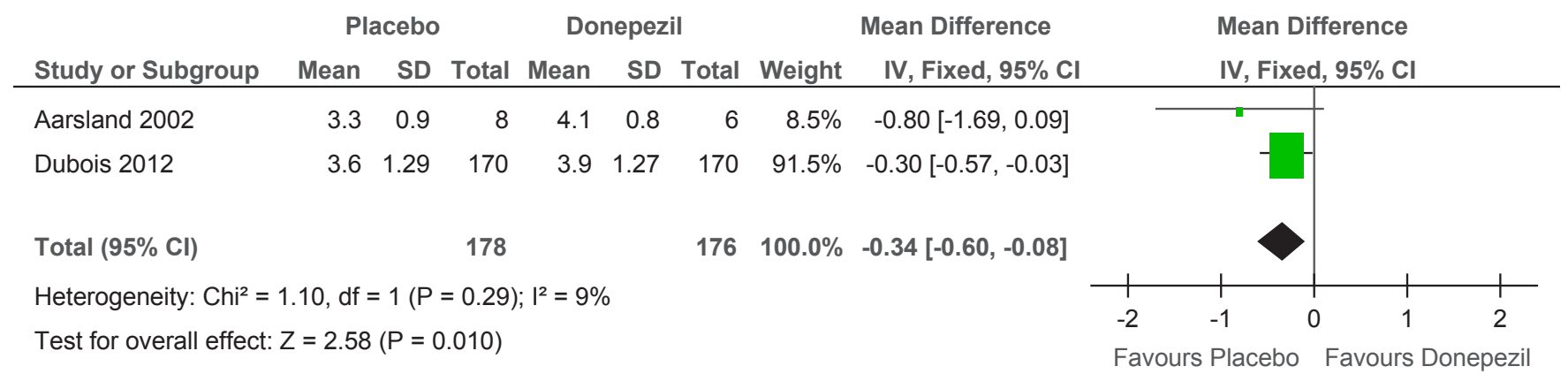

Figure 5. Comparison of the Mean Change in CIBC Scores

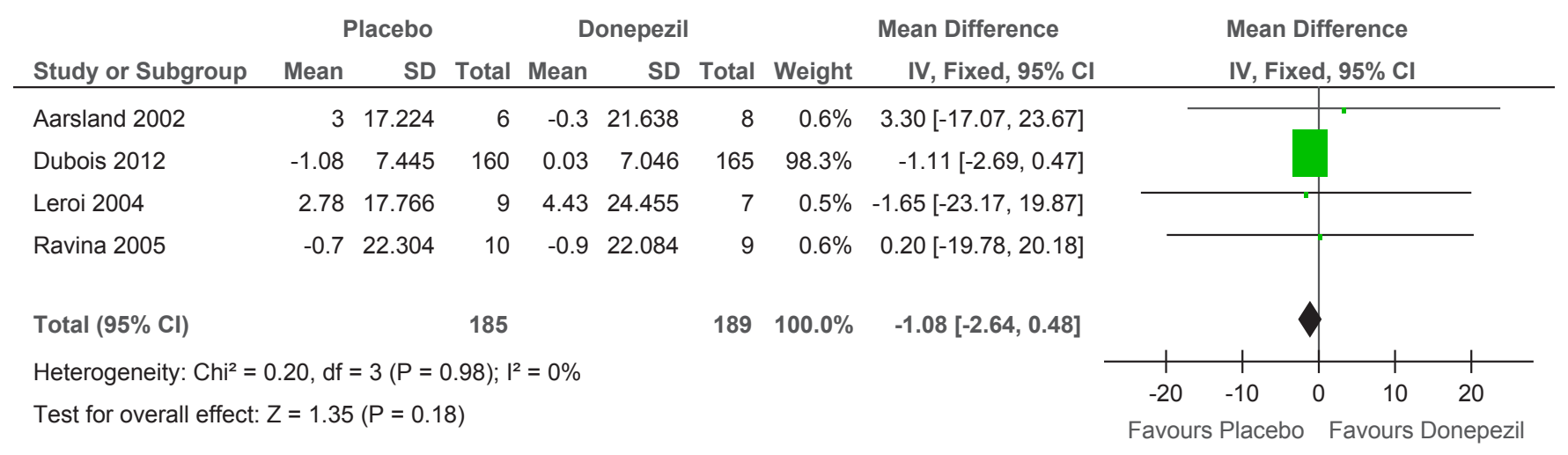

Figure 6. Comparison of the Mean Change in UPDRS Motor Scores

\section{Discussion}

Donepezil has been shown to be effective in improving cognitive function of patients with MCI and dementia as measured by change in MMSE. ADAS-Cog also showed a trend favoring Donepezil although this was not statistically significant. Furthermore, measurement of cognitive improvement by other scales such as BTA and CIBC failed to show statistically significant difference. Hence, Donepezil still has not yet established a firm ground in the management of cognitive dysfunction in Parkinson's disease patients with dementia or MCI. There are several points that can be discerned in this study explaining such claim.

Each of the cognitive scales mentioned above measures similar but not identical cognitive factors. ADAS-Cog tends to emphasize the domains of memory and language. These two domains are more severely affected in Alzheimer's disease than in Parkinson's disease. This may be the reason why ADAS-Cog failed to show statistical significance in this study. The same goes for BTA which mainly measures the ability to concentrate. ${ }^{22,23}$

On the other hand, MMSE is more commonly used as a screening tool for detecting cognitive impairment because it spans most of the cognitive domains. It may have been more sensitive in detecting change in cognitively impaired Parkinson's patients. The CIBC does not provide an objective means for detecting improvement. Hence, it is of no high value even if it were statistically significant. ${ }^{22,23,24}$

The incidence of adverse events reported was higher in donepezil compared to placebo in all of the four studies; however, none were statistically significant. Adverse events reported were nausea, vomiting, dizziness, diarrhea, hallucinations, psychosis, agitation, and arrhythmia. All the included studies concluded that Donepezil did not significantly affect the UPDRS Motor scale.

Variable cognitive scales used in the measurement of cognitive function of Parkinson's disease patients pose a big challenge for researchers to generalize results and clinicians to choose which scale can effectively monitor their patients' cognitive status. Therefore, a universally accepted cognitive assessment tool tailored especially to Parkinson's disease patients may be developed in the future.

\section{Conclusion}

This study demonstrated the efficacy of Donepezil in cognitively impaired Parkinson's disease patients in the improvement of MMSE. Consequently, the demonstration of the drug having no significant impact on the motor symptoms of PD patients as measured by the change in UPDRs makes it acceptable to administer it to such patients. However, the presence of side effects such as nausea, 
headache, insomnia, dizziness, and diarrhea, should remain a factor in a clinician's decision to administer Donepezil or not.

\section{References}

1. Van Den Eeden SK, Tanner CM, Bernstein AL, et al. Incidence of Parkinson's Disease: variation by age, gender, and race/ethnicity. Am J Epidemiol. 2003; 157:1015-22.

2. Hughes TA, Ross HF, Musa S, et al. A 10-year study of the incidence of and factors predicting dementia in Parkinson's disease. Neurology. 2000; 54(8):1596-602.

3. Aarsland D, Andersen K, Larsen JP, Lolk A, Nielsen H, Kragh-Sørensen P. Risk of dementia in Parkinson's disease: a community-based, prospective study. Neurology. 2001; 56(6):730-6.

4. Marder K, Tang MX, Cote L, Stern Y, Mayeux R. The frequency and associated risk factors for dementia in patients with Parkinson's disease. Arch Neurol. 1995; 52(7):695-701.

5. Marttila RJ, Rinne UK. Dementia in Parkinson's disease. Acta Neurol Scand. 1976; 54(5):431-41.

6. Lieberman A, Dziatolowski M, Kupersmith M, et al. Dementia in Parkinson Disease. Ann Neurol. 1979; 6(4):355-9.

7. Boller F, Mizutani T, Roessmann U, Gambetti P. Parkinson disease, dementia, and Alzheimer disease: clinicopathological correlations. Ann Neurol. 1980; 7(4):329-35.

8. Brown RG, Marsden CD. How common is dementia in Parkinson's disease? Lancet. 1984; 2(8414):1262-5.

9. Yoshimura M. Pathological basis for dementia in elderly patients with idiopathic Parkinson's disease. Eur Neurol. 1988; 28 Suppl 1:29-35.

10. Friedman A, Barcikowska M. Dementia in Parkinson's disease. Dementia. 1994; 5(1):12-6.

11. Aarsland D, Brønnick K, Fladby T. Mild Cognitive Impairment in Parkinson's Disease. Curr Neurol Neurosci Rep. 2011; 11(4):371-8.

12. Leroi I, McDonald K, Pantula H, Harbishettar V. Cognitive impairment in Parkinson disease: Impact on quality of life, disability, and caregiver burden. J Geriatr Psychiatry Neurol. 2012; 25:208-14.

13. Fernandez HH, Crucian GP, Okun MS, Price CC, Bowers D. Mild cognitive impairment in Parkinson's disease: the challenge and the promise. Neuropsychiatric Dis Treat. 2005; 1(1):37-50.

14. Dubois B, Pillon B. Cognitive deficits in Parkinson's disease. J Neurol. $1997 ; 244: 2-8$

15. Nakano I, Hirano A. Parkinson's disease: neuron loss in the nucleus basalis without concomitant Alzheimer's disease. Ann Neurol. 1984; 15:415-8.

16. Jellinger KA. Neuropathological correlates of mental dysfunction in Parkinson's disease: An Update in Mental Dysfunction in Parkinson's Disease. In: Wolters EC, Scheltens PH, Berendse HW, eds. Academic Pharmaceutical Productions, BV: Utrecht; 1999. pp. 82-105.

17. Di Santo SG, Prinelli F, Adorni F, Caltagirone C, Musicco M. A metaanalysis of the efficacy of donepezil, rivastigmine, galantamine, and memantine in relation to severity of Alzheimer's disease. J Alzheimers Dis. 2013; 35(2):349-61

18. Nagatsu T, Fisher A, Yoshida M. Basic, Clinical, and Therapeutic Aspects of Alzheimer's and Parkinson's Diseases. Vol. 2. New York: Plenum Press; 1990. pp. 409-413.

19. Rogers SL, Yamansihi Y, Yamatsu K. E2020-the pharmacology of a piperidine cholinesterase inhibitor. In: Becker R, Giacobini E, eds. Cholinergic Basis for Alzheimer Therapy. Boston: Birkhäuser; 1991. pp. 314-320.

20. Ogura H, Kosasa T, Araki S, Yamanishi Y, Yamatsu K. Behavioral study of E2020, a novel centrally acting acetylcholinesterase inhibitor. Soc Neurosci Abstr. 1988; 14:60-60. (27.21).

21. Rogers SL, Cooper NM, Sukovaty R, Pederson JE, Lee JN, Friedhoff LT. Pharmacokinetic and pharmacodynamic profile of donepezil $\mathrm{HCl}$ following multiple oral doses. Br J Clin Pharmacol. 1998; 46(S1):7-12.

22. Sheehan B. Assessment scales in dementia. Ther Adv Neurol Disord. 2012; 5(6):349-58.
23. Meade C, Bowden S. Diagnosing dementia: mental status testing and beyond. Aust Prescr. 2005; 28:11-13.

24. Jalbert JJ, Daiello LA, Lapane KL. Dementia of the Alzheimer type. Epidemiol Rev. 2008; 30:15-34. 